\title{
Desafios da Administração Pública: a gestão de escolas públicas em Teixeira de Freitas, Bahia, Brasil
}

\author{
Challenges of public administration: the management of public schools from
}

\author{
Teixeira de Freitas, Bahia, Brazil
}

\begin{abstract}
Aline Fonseca Gomes ${ }^{1 *}$; David Manuel Costa Passinhas ${ }^{1}$; Eduarda Andrade Santos ${ }^{1}$ Etiene Santiago Carneiro ${ }^{2}$; Jackeline Silva de Jesus ${ }^{1}$; Nathalya Freitas Figueredo ${ }^{1}$

${ }^{1}$ Instituto Federal de Educação, Ciência e Tecnologia Baiano - IF Baiano, Teixeira de Freitas - Bahia, Brasil, 45985-970, aline.gomes@ifbaiano.edu.br, https://orcid.org/0000-0001-9655$\underline{0047}$ *(autor correspondente); passinhas123@gmail.com, https://orcid.org/0000-0003-

3751-6169; andradeeduarda910@gmail.com, https://orcid.org/0000-0003-3465-9391; jackelinesilvadejesus4@gmail.com, https://orcid.org/0000-0001-8217-9128; nathalya.freitasfi@gmail.com, https://orcid.org/0000-0001-6659-4073
\end{abstract}

${ }^{2}$ Instituto Federal de Educação, Ciência e Tecnologia Baiano - IF Baiano, Serrinha - Bahia, Brasil, 48700-000, etiene.carneiro@ifbaiano.edu.br, https://orcid.org/0000-0003-0335-4958

\section{Resumo}

Nesta pesquisa sobre gestão escolar que objetivou de forma geral identificar os principais problemas enfrentados pelos gestores das escolas públicas municipais de Teixeira de Freitas BA, Brasil. Foi conduzida pesquisa com abordagem quali-quantitativa e descritiva com aplicação de instrumento de coleta de dados (questionário semi estruturado) junto a oito gestores de Instituições de Ensino públicas do município de Teixeira de Freitas. Por meio da pesquisa foi possível descrever alguns fatores negativos nas esferas da gestão escolar pedagógica, financeira e administrativa, além dos relatos sobre as dificuldades enfrentadas pelos gestores. Além do mais, no requisito pedagógico, foi relatado pelos entrevistados a falta do apoio e acompanhamento dos pais na vida escolar dos filhos. Como resultados da pesquisa foram identificados os problemas principais, tais como: a falta de acompanhamento, dificuldades financeiras, falta de infraestrutura, falta de ferramentas de gestão. Além disso, por desafios e perspectivas, constatou-se que a gestão escolar é uma ferramenta importante da educação e que a mesma engloba aspectos referentes à parte interna da instituição que pressupõe o planejamento e o controle.

Palavras chave: gestão, administrativa, planejamento, controle.

\section{Abstract}


In this research on school management which aimed in general to identify the main problems faced by the managers of municipal public schools from Teixeira de Freitas - BA, Brazil. Research was conducted with a qualitative-quantitative and descriptive approach with the application of a data collection instrument (semi-structured questionnaire) with eight managers of public educational institutions in Teixeira de Freitas. Through the research it was possible to describe some negative factors in the spheres of pedagogical, financial and administrative school management, in addition to reports on the difficulties faced by managers. Furthermore, in the pedagogical requirement, the interviewees reported the lack of support and monitoring by parents in their children's school life. As a result of the research, the main problems were identified, such as: lack of follow-up, financial difficulties, lack of infrastructure, lack of management tools. In addition, due to challenges and perspectives, it was found that school management is an important tool for education and that it encompasses aspects related to the internal part of the institution that presupposes planning and control.

Keywords: management, administrative, planning, control.

\section{Introdução}

Com o intuito de buscar maior qualidade no serviço público, desde 1930, projetos de lei e modelos novos foram criados para atingir esse objetivo. Entretanto percebe-se que apesar das mudanças, ainda existe obstáculos que impedem esses avanços, criando-se então um clima de insegurança e insatisfação entre os cidadãos.

Autores como Di Pietro (2012) e Vasconcellos (2000) deram as suas contribuições que são importantes para o tema que será discutido na pesquisa, além de enfocar na relação existente entre a Nova Gestão Pública e em como ela afetou o modo de gerir na educação brasileira, a partir de um método que surge da necessidade de se ter eficácia nos processos internos da instituição: a gestão escolar democrática e participativa, onde existe uma relação de troca entre a própria escola e a comunidade que a cerca.

Essa pesquisa foi importante para levar fatos desconhecidos que cercam a gestão pública das escolas municipais do município de Teixeira de Freitas. Os pesquisadores já foram alunos de escolas públicas durante o ensino fundamental e são alunos de instituição pública no ensino médio. Segundo dados do IBGE (2017), "no Brasil, 56,5 milhões de pessoas frequentavam escola ou creche no ano passado. Do total de estudantes, 73,5\% frequentavam escola pública, enquanto $26,5 \%$, a rede privada", e nisso observa-se a tamanha relevância que as escolas 
públicas têm em nosso país, atendendo as necessidades da maioria dos alunos que procuram esse sistema como uma das maneiras de obter o aprendizado devido. Por isso a pesquisa é viável, pois assim se descobrirá de alguma forma como a gestão pública afetou o desenvolvimento das formações futuras dos alunos.

Contudo, segundo IBGE (2017), estima-se que cerca de 24,8 Milhões das pessoas de 14 a 29 anos não frequentam escolas nem qualquer outro meio de educação. Sem a instrução, o indivíduo fica à deriva de sua própria ignorância, visto que não há combate à pobreza, crescimento econômico, diminuição da violência, conscientização para proteger o meio ambiente, aumento da satisfação pessoal e compreensão dos acontecimentos do mundo.

Diante do exposto, o problema de pesquisa foi: Quais são os desafios e perspectivas da administração pública na gestão de escolas públicas em Teixeira de Freitas, Bahia, Brasil? Acredita-se, assim, que as pesquisas que existem sobre esse tema podem contribuir para a gestão pública em escolas municipais. Logo, o objetivo geral da pesquisa foi o de identificar os principais problemas enfrentados pelos gestores das escolas públicas municipais no município de Teixeira de Freitas. Por objetivos específicos têm-se os seguintes: traçar o perfil de gestores de escola pública; identificar a existência de projeto político pedagógico; destacar os benefícios que uma boa administração pode proporcionar para a melhoria do processo ensino e aprendizagem; sugerir uma ferramenta de gestão para ser utilizada pelos gestores das escolas públicas.

\section{Administração Pública e Gestão Escolar}

Percebe-se que o conceito atual dado à administração pública não se mostra adequado no atendimento das exigências para eficácia das normas constitucionais. Entretanto pode-se entender que ela é o exercício do poder exercido pelo povo, incluindo o Poder Executivo, o Legislativo e o Judiciário, atividades que devem estar obedecendo aos princípios da administração pública.

Para Di Pietro (2012) o Direito Administrativo é o ramo do direito positivo que rege a administração pública como forma de atividade, além de definir quais são as pessoas administrativas, a organização e os agentes do Poder Executivo, ou seja, é um conceito da área 
do direito que especifica o conjunto de agentes, serviços e órgãos controlados pelo Estado brasileiro com o objetivo de gerir certas áreas que pertencem ao coletivo de uma sociedade, podendo ser: educação, saúde e cultura, por exemplo.

Segundo Di Pietro (2012), existem duas maneiras de se interpretar o sentido da administração pública: sendo que uma delas é chamada de subjetivo, orgânico ou formal, segundo o qual essa expressão alcançaria as pessoas jurídicas, seus órgãos e agentes que executam a atividade administrativa; e a outra é o objetivo, material, operacional ou funcional.

Percebe-se que a administração pública pode se adequar a esses dois sentidos, a partir do modo de como é exercida e utilizada nas entidades, não só públicas como também organizações privadas, a exemplo das Organizações não Governamentais - ONGs, que de alguma forma estão entrelaçadas com o dia a dia de alguma comunidade, podendo auxiliar o Estado onde se está tendo carência de certa área que é de extrema necessidade para a sociedade.

Nesse sentido, a administração pública pode ter tanto uma função política ou de governo, segundo Di Pietro (2012) implica uma atividade de ordem superior referida à direção suprema e geral do Estado em seu conjunto e em sua unidade, dirigida a determinar os fins da ação do Estado, a assinalar as diretrizes para as outras funções, buscando a unidade da soberania estatal.

No Brasil existiram três tipos de modelos de administração pública: o Patrimonialismo, Burocrático e Gerencial. Segundo Fernandes (2021), o Patrimonialista é característica dos Estados absolutistas, em que apenas uma pequena parcela das pessoas (a nobreza) tem propriedade sobre as terras e não há uma diferenciação clara entre o que é público e o que pertencente ao rei. Nesse modelo, as pessoas que vão assumir os cargos públicos são indicadas pelo soberano/líder e essa versão patrimonialista foi abolida com o fim das monarquias absolutistas e a ascensão da burguesia e do Estado liberal. Porém no Brasil ela ainda foi constante na República Velha (1889-1930).

A palavra burocracia vem do francês bureau, que significa simplesmente escritório, não tendo em suas origens a conotação negativa que hoje costumamos dar, como se tratava de um método lento e retrógrado. Esse modelo foi inicialmente proposto por Max Weber e deveria significar apenas uma forma de organização em que é de suma importância prevalecer às regras e os procedimentos, com divisão (CURADO, 2019). 
Então, por fim, o modelo gerencial chega aos anos 90, já que foi percebido que o modelo anterior não estava acompanhando as mudanças que o mundo todo estava passando. Também conhecida "Nova Gestão Pública", ela vem como uma crítica ao behaviorismo, em que o comportamento de um único indivíduo vai explicar o comportamento coletivo, para ela a ação social é determinada por instituições, pois influenciam os atores sociais (SIQUEIRA JR., 2013).

Desse modo, a Nova Gestão Pública - NGP surge em oposição à administração pública, buscando inovar tanto nos modos de organizar e gerir a coisa pública, quanto também os novos modos de governo, onde os resultados são priorizados.

Sobre a importância da administração pública, percebe-se que muitos autores tratam da defesa dos interesses sociais e da comunidade, da garantia do bem-estar social oferecido pela Administração Pública, e do zelo pelo bem comum da coletividade. Como toda profissão, há quem a pratique de forma ética e correta; como também há os que a praticam de forma antiética e ilegal. Por lei, o infrator pode ser julgado por Improbabilidade Administrativa, de acordo a Lei $n^{\circ} 8.429$ de 2 de Junho de 1992.

Entende-se então, que a Administração Pública é importante, pois trabalha a favor do interesse público e dos direitos e interesses dos cidadãos que administra, proporcionando maior segurança e bem-estar, isto, quando é praticada de maneira correta. Segundo Di Pietro (2012), o entendimento é de que a Administração Pública trata do coletivo de todos os órgãos que vão autoriza os serviços do Estado que compreendem o seu aparelho administrativo e suas determinadas utilidades, ou seja, não somente no sentido formal, por meio de seus órgãos, mas também como atividade, dada às tarefas orientadas para a movimentação o que é importante no funcionamento de governos.

Em relação especificamente a gestão escolar, destaca-se que partindo do conceito de Escola, têm-se que a mesma, é a instituição que fornece o processo de ensino para discentes, com o objetivo de formar e desenvolver cada indivíduo em seus aspectos cultural, social e cognitivo, conforme Brasil Escola (2020). Assim, a gestão escolar pode ser compreendida como um sistema de organização que engloba todos os setores referentes ao desenvolvimento escolar na parte interna. Entretanto, é de extrema importância que cada escola possua o seu plano de gestão, pois com esse aspecto a instituição pode ter um melhor desempenho no ensino, uma 
redução dos descumprimentos das obrigações, maior motivação dos funcionários ao atuarem em sua área, um melhor engajamento dos alunos e dos pais aos projetos escolares e entre outras melhorias.

Sendo assim, o gestor escolar é o responsável por atuar nessa área, e a sua função é elaborar propostas para o aprimoramento do ensino, além de que também deve ajudar os estudantes a desenvolverem as suas habilidades.

De acordo com Santarém (2016), a gestão escolar é dividida em quatro principais pilares, que são:

- Gestão pedagógica que organiza, planeja e administra na área educativa;

- Gestão administrativa que trata da organização e administração da instituição como estrutura física;

- Gestão financeira que cuida de toda a parte financeira da instituição (cálculo de custos, fluxo de caixa, definição de orçamento, entre outras atividades);

- Gestão de recursos humanos com a organização de toda a comunidade que faz parte do ambiente escolar.

Segundo Santarém (2016), pode-se organizar a gestão escolar em 10 dimensões, dentre elas duas delas são: as dimensões de organização baseada nos fundamentos e princípios da educação e da gestão escolar, além do planejamento e organização do trabalho escolar, monitoramento de processos e avaliação institucional e da própria gestão de resultados educacionais; as dimensões de implementação são aquelas mais diretamente vinculadas à produção de resultados, tais como a gestão democrática e participativa, a gestão de pessoas, gestão pedagógica, gestão administrativa, a gestão da cultura escolar e a gestão do cotidiano escolar.

Para Pereira (1998), uma reforma efetiva deve começar primeiramente pela valorização dos servidores, ao investir em seu aperfeiçoamento e treinamento, ao dar-lhes a oportunidade de progredir profissionalmente, por meio de planos de carreira, e ao adotar procedimentos rígidos de controle sobre sua estabilidade no cargo, por isso o aprimoramento do servidor deveria ser algo constante e produtivo, porém, têm assumido um caráter mais abstrato e repressivo. 
Acredita-se que a maior parte das gestões escolares tem preferido adotar modelos que dão oportunidade da comunidade que está atrelada a ter uma participação ativa, um exemplo a se citar é a gestão democrática e participativa, instituída na Constituição Federal (Art. 206, inciso VI), onde dão o direito de toda a comunidade escolar, de pais, alunos e professores a participar da organização escolar, ou seja, uma relação de parceria que têm como pilares: a descentralização, a participação e a transparência.

Assim, para que os três pilares sejam efetivamente alcançados, convém destacar a relevância do Projeto Político Pedagógico - PPP para a gestão escolar, contextualizando que surgiu no artigo 206, inciso VI da Constituição da República de 1988, que estabelece como princípio do ensino público, a Gestão Democrática. Segundo Vasconcellos (2000), o projeto político-pedagógico é o plano global da instituição. Pode ser entendido como a sistematização, nunca definitiva, de um processo de planejamento participativo, que se aperfeiçoa e se concretiza na caminhada, que define claramente o tipo de ação educativa que se quer realizar. É um instrumento teórico-metodológico para a intervenção e mudança da realidade. É um elemento de organização e integração da atividade prática da instituição neste processo de transformação.

Entretanto, o PPP é visto como uma ferramenta burocrática que torna o processo de tomada de decisão Institucional, lento e retrógrado quando não é adequado às exigências e precisões da instituição. Podendo inclusive gerar frustração entre corpo docente e discente da escola. Fatores que reforçam a necessidade de escutar os atores sociais antes da construção do Projeto Político Pedagógico (PPP), pois dessa maneira todas as partes poderão contribuir com sugestões e/ou críticas construtivas para criação de uma espécie de 'identidade da escolar' que é idealizada, analisando a realidade dela junto à comunidade, para depois construir texto colaborativo materializando as ideias e discussões que se concluíram.

\section{Material e Métodos}

A pesquisa foi do tipo descritiva, pois visou descrever as dificuldades da gestão escolar das escolas pesquisadas. Foi feita revisão sistemática, adotando uma questão específica e cuja avaliação é reprodutível para outras Instituições de Ensino. Segundo as fontes de coleta de 
dados, foram utilizadas pesquisas bibliográficas, além de pesquisa de campo e por instrumentos de coleta aplicaram-se questionários. Assim, a pesquisa, com base nos procedimentos técnicos utilizados, foi do tipo bibliográfica e pesquisa de campo.

A temática administração pública, com o foco na gestão escolar, foi escolhida buscando formular um problema de pesquisa sobre quais são os desafios e perspectivas da administração pública na gestão de escolas públicas no município de Teixeira de Freitas - Bahia. Tal formulação da pergunta de partida utilizou-se da estratégia PICO - Paciente, Intervenção, Comparação e Outcomes (desfecho), em que se buscam evidências para o fato em que se está investigando, ressaltando que a população escolhida foi bem delimitada a partir da escolha de uma amostra intencional.

O presente trabalho utilizou o método de pesquisa de natureza quali-quantitativa, com aplicação do instrumento de coleta de dados nas escolas públicas municipais de Teixeira de Freitas, nas quais houve a participação de 8 Instituições de Ensino, sendo que em cada instituição foi entrevistado um gestor, com o objetivo de colher os dados sobre a gestão escolar através de questionário semi-estruturado, conforme dados abaixo, tendo por corte temporal os semestres 2019.2 e 2020.1 .

O questionário continha as seguintes questões:

1-Liste as principais dificuldades enfrentadas na gestão escolar nas esferas pedagógica, administrativa e financeira: a) acompanhamento dos pais b) indisciplina e a não educação em casa dos filhos por parte dos pais c) falta de livros didáticos d) falta de material para a realização de atividades e) pouco recurso distribuindo para a instituição f) dificuldades com a infraestrutura;

2-A sua instituição de ensino possui PPP? a) sim b) não;

3-Quais foram os envolvidos na elaboração do PPP? a) pais dos alunos b) alunos c) professores d) comunidade de Teixeira de Freitas d) outros;

4-Qual a relevância do PPP na gestão escolar? a) serve como norteador para o bom desenvolvimento da unidade escolar b) direciona atividades pedagógicas e administrativas da escola c)é a "cabeça" de tudo, e também a direção d)direcionar o trabalho, traçar metas a serem cumpridas e diagnosticar os problemas e)É o documento de grande relevância f)norteiam as 
ações serem tomadas;

5- Marque quais as atividades extracurriculares são realizadas com a comunidade? a) projeto de pesquisa b) projeto de extensão c) eventos comemorativos d) palestras;

6- Marque quais Atividades extracurriculares no campo pedagógico são desenvolvidas pela sua instituição de ensino? a) reforço aos alunos b) aquisição de livros didáticos c) palestras d) passeios escolares;

7- Com é a relação entre a escola e a comunidade de Teixeira de Freitas?

Portanto, a partir da definição do questionário foram escolhidos os sujeitos da pesquisa que da população total de 137 escolas no município de Teixeira de Freitas, encontrou-se o dado de que 26 destas são públicas e que conforme dados da plataforma Qedu (2019) participaram da Prova Brasil em 2017. Assim, apenas 21 escolas são municipais, públicas e urbanas, também conforme dados do Qedu (2019), apresentados na tabela 1, deste estudo. Logo, por acessibilidade e proximidade de localização foram escolhidas 8 escolas e pesquisados seus gestores, correspondendo a amostra da pesquisa que foi do tipo não aleatória e intencional.

Nesse sentido, destaca-se que a análise dos dados obtidos através das pesquisas de campo foi apresentada em forma de gráficos do tipo foram do tipo barra para comparação dos dados quantitativos e assim fornecer subsídios para análises. Destaca-se que não houve financiamento da referida pesquisa.

\section{Resultados}

Acredita-se que o gestor escolar é um dos cargos mais importantes, pois é ele que dá aos alunos o privilégio de uma educação de qualidade. A função do gestor escolar pode ser dividida em dois setores: o diretor e o coordenador. $\mathrm{O}$ gestor também é atuante em três áreas, como a administrativa, pedagógica e a gestão de comunidade. É possível reconhecer que o mesmo, além de prezar pela educação dos alunos, também tem uma participação na elaboração do PPP, e cuida das questões financeiras da escola, para que não falte nada de materiais e alimento aos alunos, sendo assim os recursos básicos para dar aos alunos um melhor aconchego e motivação aos estudos.

Apresenta-se que o total das escolas do município de Teixeira de Freitas que são públicas 
e que conforme dados do Qedu (2019) participaram da Prova Brasil, em 2017, e são as 26 que se encontram dispostas na tabela 1 , conforme apresentadas na metodologia deste estudo.

Tabela 1. Localização e quantitativo de escolas municipais de Teixeira de Freitas

\begin{tabular}{l|c|c}
\hline \multicolumn{1}{c|}{$\begin{array}{c}\text { Bairro de Teixeira de } \\
\text { Freitas }\end{array}$} & $\begin{array}{c}\text { Quantidade de } \\
\text { Escolas }\end{array}$ & Zona \\
\hline Bela Vista & 02 & Urbana \\
\hline Bonadimam & 01 & Urbana \\
\hline Centro & 03 & Urbana \\
\hline Distrito & 02 & Rural \\
\hline Duque de Caxias & 01 & Urbana \\
\hline Jardim Caraípe & 01 & Urbana \\
\hline Jardim Novo & 01 & Rural \\
\hline Jerusalém & 01 & Urbana \\
\hline Liberdade & 01 & Urbana \\
\hline Luis Eduardo Magalhães & 01 & Urbana \\
\hline Nova Aliança & 01 & Urbana \\
\hline Redenção & 02 & Urbana \\
\hline Residencial dos Pioneiros & 01 & Urbana \\
\hline Santa Rita & 01 & Urbana \\
\hline Santo Antônio & 01 & Rural \\
\hline São Lourenço & 02 & Urbana \\
\hline São Pedro & 01 & Urbana \\
\hline Tancredo Neves & 01 & Urbana \\
\hline Ulisses Guimarães & 01 & Urbana \\
\hline Urbis II & 01 & Urbana \\
\hline & 26 & - \\
\hline Fonte: Adaptado & &
\end{tabular}

Fonte: Adaptado de Qedu (2019).

Nesse sentido, apresenta-se os gráficos a partir da tabulação dos dados da pesquisa de campo realizada com os 8 gestores das escolas públicas de Teixeira de Freitas - Bahia: 


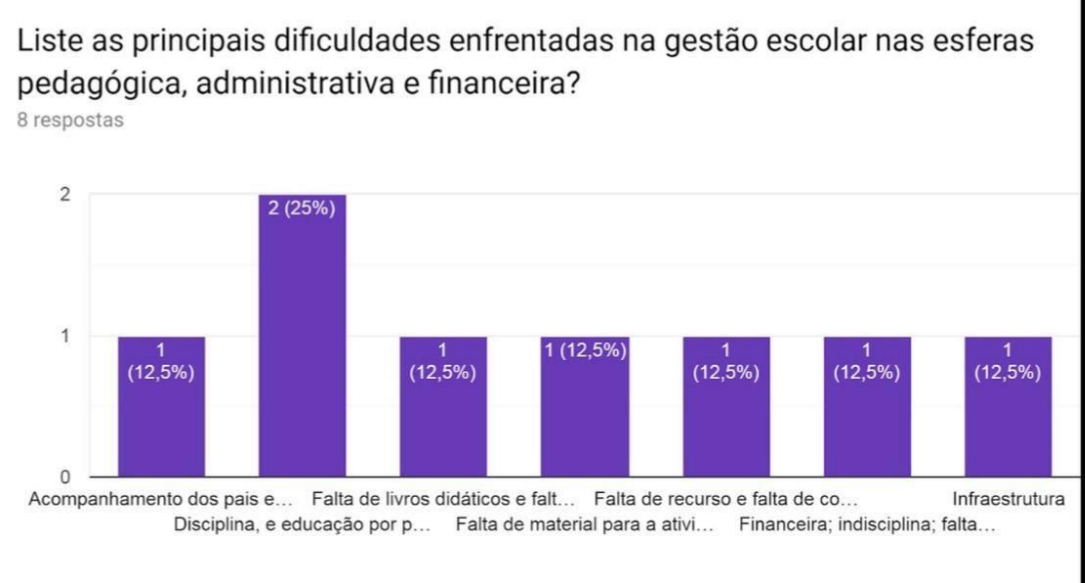

Gráfico 1. Principais dificuldades enfrentadas na gestão escolar

Analisando o gráfico 1, percebe-se que 12,5\% dos entrevistados, afirmaram ter maior dificuldade na questão que remete ao acompanhamento dos pais na escola de seus filhos, consequência da desestrutura familiar; $25 \%$ relataram ser a indisciplina e a não educação em casa dos filhos por parte dos pais; $12,5 \%$ disseram que o maior problema está na falta de livros didáticos; $12,5 \%$ nos contaram que a maior dificuldade enfrentada é a falta de material para a realização de atividades, uma consequência das verbas insuficientes; $12,5 \%$ responderam que têm como maior dificuldade o pouco recurso distribuindo para a instituição e a falta de compromisso dos pais; $12,5 \%$ explicitaram como dificuldades enfrentadas: a questão financeira, a indisciplina dos alunos, e a falta de acompanhamento dos pais; e por fim, 12,5\% mostraram enfrentar dificuldades maiores na infraestrutura.

Como $100 \%$ dos entrevistados disseram que a instituição em que trabalham possui PPP (projeto político pedagógico). Isso se deve ao fato do mesmo ser de suma importância, pois contém as diretrizes e metas que a escola deve seguir para garantir uma boa administração nas esferas que compõem a gestão de uma instituição. Ajudando na orientação cotidianamente com o objetivo de alcançar um ótimo resultado na área da educação, podendo ofertar para a comunidade em que se situa um ensino de alta qualidade. 
Quais foram os envolvidos na elaboração do PPP?

8 respostas

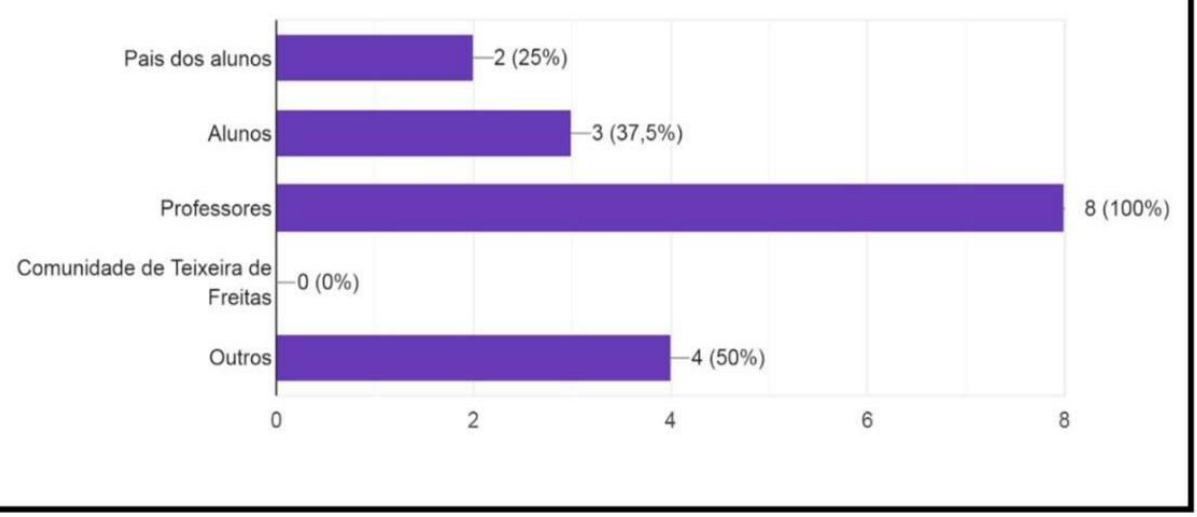

Gráfico 2. Envolvidos na elaboração do PPP

Em relação ao gráfico 2, dentre os entrevistados, 25\% afirmaram que os pais dos alunos ajudaram na elaboração do PPP (projeto político pedagógico); 37,5\% disseram que houve a participação dos alunos; $100 \%$ responderam que contaram com a ajuda dos professores para a elaboração do PPP; e 50\% responderam que houve a ajuda de outros meios para a elaboração do mesmo. Assim, o PPP tem a função de guiar a instituição de ensino para que a mesma possa atingir suas metas e objetivos. Ressalta-se que no referido questionamento poderia marcar mais de uma alternativa.

Qual a relevância do PPP na gestão escolar?

8 respostas

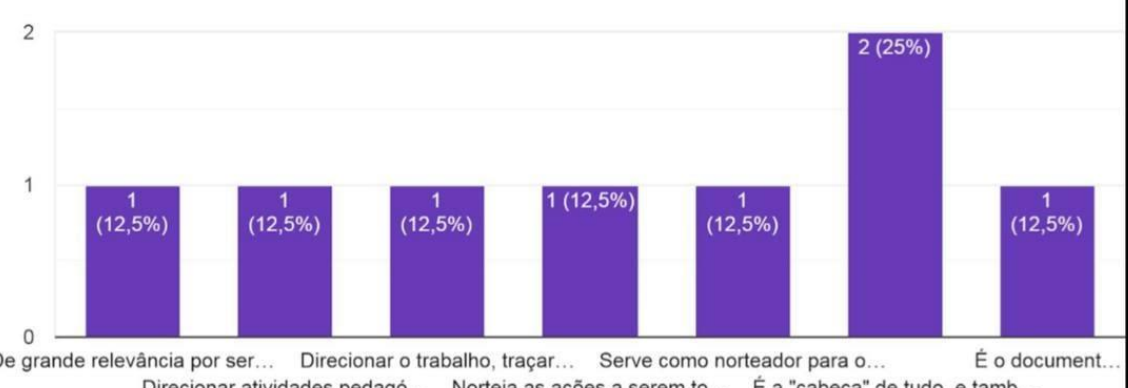

Direcionar atividades pedagó... Norteia as açōes a serem to... É a "cabeça" de tudo, e tamb...

Gráfico 3. Relevância do PPP na gestão escolar 
Dentre as pessoas entrevistadas, na questão que discutia a relevância do PPP para a gestão escolar, $12.5 \%$ responderam que serve como norteador para o bom desenvolvimento da unidade escolar, $12.5 \%$ falou que direciona atividades pedagógicas e administrativas da escola, 12,5\% afirmaram que é a "cabeça" de tudo, e também a direção, 25\%, a que segue como líder no gráfico, falaram que o PPP é para direcionar o trabalho, traçar metas a serem cumpridas e diagnosticar os problemas.

E o restante, ainda sobre o gráfico 3, em uma análise contínua de $12,5 \%$ responderam que é de grande relevância para o seu documento norteador, 12,5\% afirmaram que norteiam as ações serem tomadas e que é de suma importância e por fim 12,5\% afirmaram é um documento norteador, sendo importante para direcionar as instituições de ensino, visando melhorar as questões financeiras, administrativa e melhorar o uso de equipamentos e materiais básicos para que o ambiente seja adequada para um ensino de qualidade.

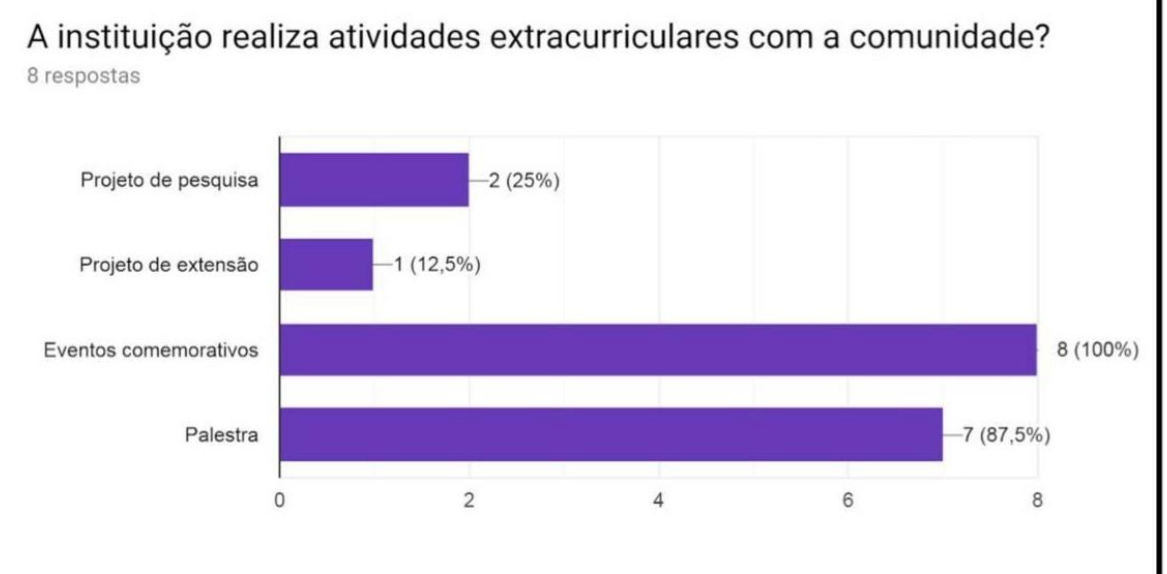

Gráfico 4. Atividades extracurriculares

Em relação aos resultados tabulados e apresentados no gráfico 4, ademais, 87,5\% disseram que realizam palestras em sua instituição com temas voltados a área da educação e informação, já que é um meio de interação não só com os alunos, mas sim com a comunidade também. Além disso, 25\% afirmaram que realizam projetos de pesquisa na instituição e $12,5 \%$ disseram que realizam projetos de extensão. Destaca-se que poderia ser marcada mais de uma alternativa para o referido questionamento. 


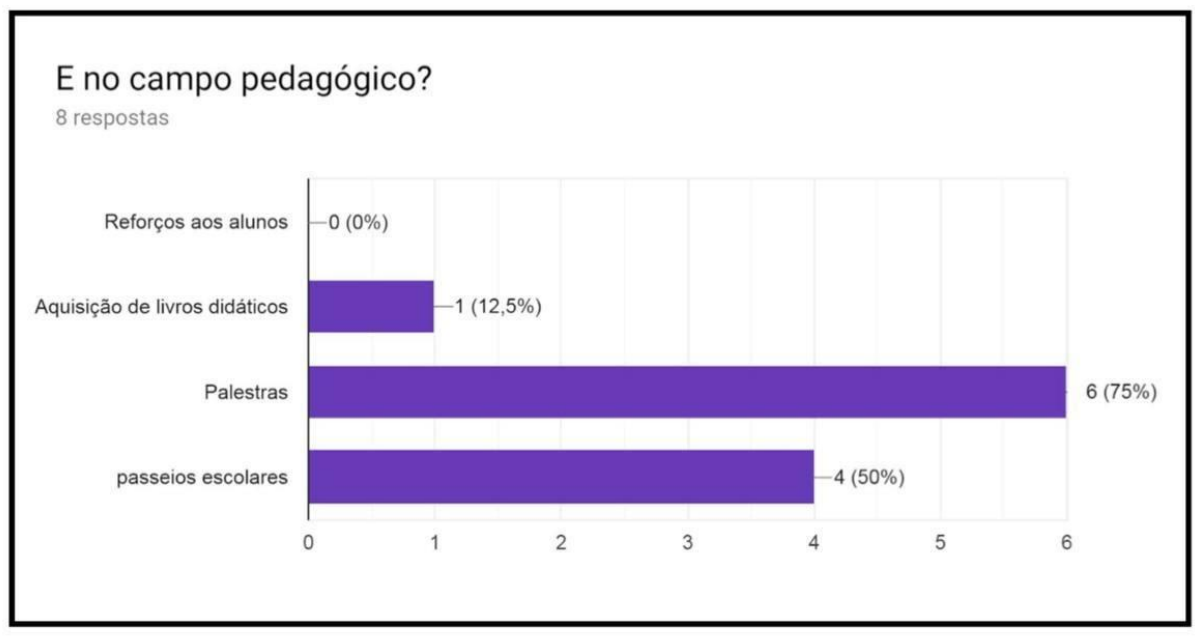

Gráfico 5. Atividades extracurriculares no campo pedagógico

Sobre os resultados apresentados no gráfico 5 , onde poderia ser marcada mais de uma alternativa, ninguém se manifestou quanto o reforço ou atendimento aos alunos que possuíam alguma dificuldade específica. Provavelmente às escolas não possuem uma estrutura adequada para fornecer ao estudante um apoio além das aulas ministradas pelo professor, o que pode deixar o mesmo com um grande déficit de aprendizado e atrasado em relação aos outros alunos, e isso pode deixá-lo cada vez mais desmotivado para estudar.

No entanto, $12,5 \%$ colocou em pauta a aquisição de livros didáticos, que muitas vezes demoram a chegar às mãos dos estudantes, atrapalhando o andamento das aulas, pois é a partir dele que o professor poderá seguir os conteúdos adequados para abordar em determinado ano, e o aluno que não possui acesso à internet pode usá-lo para estudar e fazer às atividades para aprender a matéria.

Todavia, 75\% viram que houve um aumento no número de palestras. É através delas que o aluno poderá ter contato com assuntos dos quais estão além do que lhe é provido em campo escolar. Contudo, 50\% acreditam que os passeios escolares como visitas técnicas foram uma grande conquista e podem complementar o aprendizado dos alunos, atuando como uma espécie de aula prática além de fornecer experiências novas aos mesmos. 


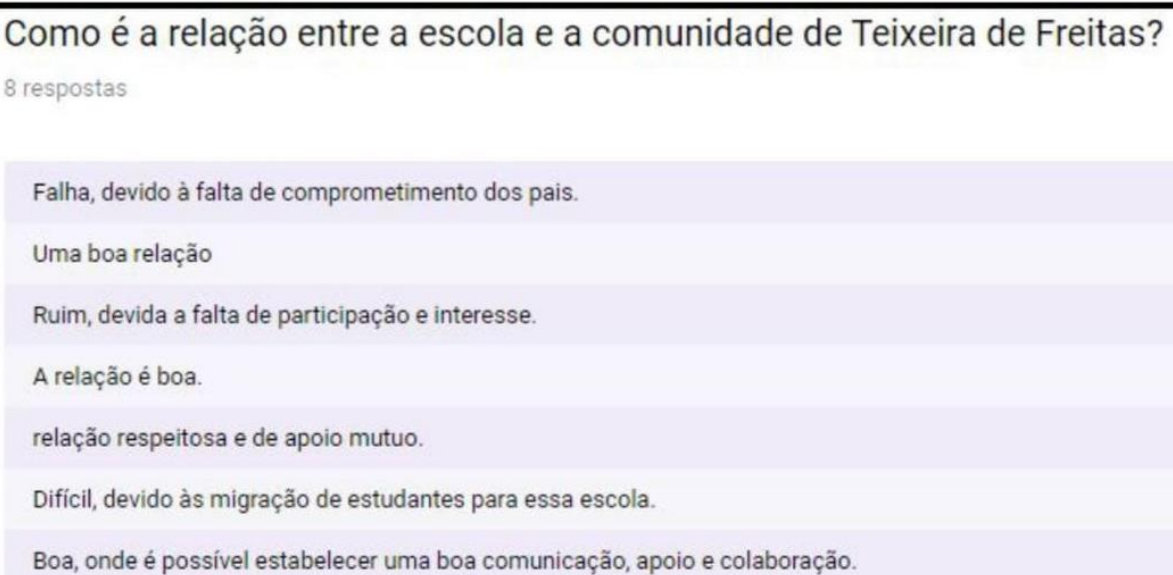

Figura 1. Relação com a comunidade

Sobre os resultados apresentados na figura 1, de acordo com os dados obtidos com os questionários, os diretores relataram que possui muita dificuldade em se relacionar com a comunidade, visto que muitos pais não vão às escolas quando tem reunião e acabam deixando sob responsabilidade da escola orientar em seu comportamento no ambiente escolar. Entretanto, não são todas as escolas que tem em sua maioria esse tipo de problema, por isso alguns relataram que têm uma boa relação com a comunidade, já que os pais participam da vida escolar de seus filhos e estão presentes nas reuniões que são realizadas nas escolas.

\section{Discussão}

A partir da pesquisa de campo que foi realizada sobre a gestão escolar, na esfera pedagógica, destaca-se que muitos dos diretores disseram que sentem a carência no acompanhamento dos pais na vida acadêmica do seu filho, passando esta tarefa para a escola, afirmaram ainda que a falta de disciplina de alguns alunos é a gestão da escola que tem de interferir e orientar seus discentes, mas nem sempre isso é eficaz, já que necessitam da participação dos pais nessa questão.

$\mathrm{Na}$ esfera financeira, todos os gestores pesquisados disseram que sofrem com a questão de verbas enviadas pelo governo, os gestores dizem que são insuficientes e dificultam na gestão escolar. Isso acaba limitando as ações que poderiam ser realizadas para contribuir no 
aprimoramento da educação que é oferecida pelas instituições, e com a falta de verbas, veio também a escassez de materiais escolares que auxiliam os alunos na realização de tarefas educativas.

Já na esfera administrativa, alguns dos entrevistados disseram que manter uma boa relação com os colegas de trabalho, é a maior dificuldade enfrentada, já que alguns acabam levando os problemas de casa para a escola, o que jamais deve ocorrer, pois é necessário que haja um ambiente harmonioso entre os colegas de trabalho para o bom desempenho de seus serviços, já que muitas têm o papel de educar seus alunos, é o papel do diretor é tentar amenizar e retirar esse tipo de conflito existente na instituição. Em convergência, Souza (2019) apresenta que há o reconhecimento de uma forte marca de gênero na função dirigente escolar, mas ao mesmo tempo, para um reconhecimento de uma face pedagógica da democracia, uma vez que há evidências de que a existência de instrumentos de gestão democrática que instigam a escola a se tornar ainda mais democrática.

Certamente, outro problema que atrapalha na relação relatada pelos diretores seria a distância da escola até o local de moradia dos alunos, já que uma parte de seus estudantes mora em bairros que se localizam muito longe da escola em que estudam, e isso acaba dificultando na interação da instituição com as comunidades distantes.

A atual pesquisa teve como maior desafio identificar os principais problemas enfrentados pelos gestores das escolas públicas municipais no município de Teixeira de Freitas; traçando o perfil de gestores; identificando a existência de projeto político pedagógico; e destacando os benefícios que uma boa administração pode proporcionar para a melhoria do processo ensino e aprendizagem. E só foi possível chegar aos resultados, através de oito entrevistas em diferentes escolas municipais de Teixeira de Freitas.

Nesse sentido, sugere-se a utilização de ferramentas de gestão e de controle para o acompanhamento do desempenho das escolas, a exemplo do Ciclo PDCA, que segundo Silva et. al (2019): com a pesquisa constaram que o ciclo PDCA é uma ferramenta que pode contribuir para a eficiência da gestão escolar, pois fornece uma estrutura para a aplicação de métodos de melhoria contínua alicerçados pela teoria do conhecimento gerencial, bem como pode ser utilizado nas mais diversas realidades e instituições de ensino. 
Destaca-se ainda que através da pesquisa realizada com as Instituições de Ensino, constatou-se que a gestão escolar é uma ferramenta importante da educação e que a mesma engloba aspectos referentes à parte interna da instituição. No entanto, o papel do gestor escolar é fundamental, pois é ele que toma decisões. Assim, ter um plano de gestão é fundamental para suprir com seus objetivos e metas, sendo o PPP um documento de extrema importância que visa guiar a instituição pelo melhor caminho; além de abordar questões pedagógicas, administrativas e financeiras, visando atingir seu propósito de maneira mais eficiente.

Nos resultados da pesquisa, constatou-se que os principais problemas que os gestores vêm enfrentando, são: a falta de acompanhamento e interesse por parte dos pais dos alunos, que de acordo com os gestores, esse acontecimento é evidente durante eventos nos quais os pais são convidados e não comparecem; dificuldades financeiras, já que a verba que é destinada para as escolas nem sempre acaba suprindo as necessidades; infraestrutura que não atende às necessidades físicas da escola, e um exemplo disso, podem ser a falta de um laboratório de informática, ou a inexistência de uma biblioteca adequada, bem como a falta de livros didáticos, o que não deveria de modo algum ocorrer, pois sem eles, essas crianças não terão acesso à educação de qualidade.

\section{Referencias}

BRASIL. Constituição (1988). Constituição da República Federativa do Brasil. 35. ed. São Paulo: Saraiva, 2006.

BRASIL. Lei n. ${ }^{\circ} 8.429$ de 02 de junho de 1992. Disponível em: https://www.camara.leg.br/proposicoesWeb/prop mostrarintegra;jsessionid=2D434A6C 7309 7403AF34BBD297333653.node1 codteor $=422375 \&$ filename $=$ LegislacaoCitada+PL+7528/2006. Acesso em: $12 \mathrm{dez} 2019$.

BRASIL ESCOLA. Função social da escola. Disponível em: $<$ https://meuartigo.brasilescola.uol.com.br/educacao/funcao-social-escola.htm $>$. Acesso em: 10 jun. 2020.

CURADO, A. Burocracia - o que é, história, Max Weber e burocracia no Brasil. Disponível em:

https://conhecimentocientifico.r7.com/burocracia/\#: : :text=A\%20palavra\%20burocracia $\% 20 \mathrm{v}$ em $\% 20$ do,governo $\% 20$ franc $\% \mathrm{C} 3 \%$ AAs $\% 20 \mathrm{no}^{2} 20 \mathrm{~s} \% \mathrm{C} 3 \% \mathrm{~A} 9 \mathrm{culo} \% 20 \mathrm{XVIII}$. Acesso em: 06 
mar. 2021.

DI PIETRO, M. S. Z. (2012). Direito administrativo. 25 ed. São Paulo, Atlas.

FERNANDES, C. Patrimonialismo. Brasil Escola. Disponível em: https://brasilescola.uol.com.br/politica/patrimonialismo.htm. Acesso em: 08 mar. 2021.

GIL, A. C. (2007). Como elaborar projetos de pesquisa. 4. ed. São Paulo: Atlas.

IBGE (2017). Ensino básico tem 73,5\% dos alunos em escolas públicas. Disponível em: http://agenciabrasil.ebc.com.br/educacao/noticia/2017-12/ensino-basico-tem-735-w dosalunos-em-escolas-publicas-diz-ibge . Acesso em: 09 jun. 2019.

PEREIRA. L. C. (1998). Gestão do setor público: estratégia e estrutura para um novo Estado. In: BRESSER PEREIRA. L.C. e SPINK, P. (org). Reforma do Estado e Administração Pública Gerencial. Rio de Janeiro: FGV.

QEDU. Lista completa de escolas, cidades e estados. Disponível em: $<$ https://www.qedu.org.br/busca $>$. Acesso em: 10 mar. 2019.

SANTARÉM, C. M. (2016). Fundamentação e princípios da educação e da gestão escolar. Disponível em: https://slideplayer.com.br/slide/10110515/. Acesso em: 09 jun. 2019.

SILVA, R. O. et. Al.. (2019). O ciclo PDCA como proposta para uma gestão escolar eficiente. Revista de gestão e avaliação educacional. v. 8, n. 17. Disponível em: https://periodicos.ufsm.br/regae/article/view/36102. Acesso em: 11 jan. 2021.

SIQUEIRA JR., G. F. (2013). Sob o véu do modelo gerencial: a implantação de instrumentos de gestão gerencial no IFPE à luz da nova administração pública. Dissertação de Mestrado, Programa de Pós-graduação em Gestão Pública para o Desenvolvimento do Nordeste. UFPE, Brasil. 141p. Disponível em: < https://repositorio.ufpe.br/handle/123456789/11378 >. Acesso em: 01 jun. 2020.

SOUZA, Â. R. Perfil da gestão da escola pública no brasil: um estudo sobre os diretores escolares e sobre aspectos da gestão democrática. Disponível em: $\leq$ https://www.researchgate.net/publication/28291737_Perfil_da

gestao_da_escola_publica_no_Brasil_um_estudo_sobre_os_diretores_escolares_e_sobre_asp ectos_da_gestao_democratica>. Acesso em: 20 de outubro de 2019.

VASCONCELLOS, C. S. (2000). Planejamento: projeto de ensino- aprendizagem e projeto político pedagógico. $9^{\mathrm{a}}$ ed. São Paulo: Libertad. 


\section{Direitos autorais (Copyrights)}

Financiamento: Esta pesquisa não recebeu nenhum financiamento.

Conflitos de interesse: Os autores declaram não haver conflitos de interesse.

Aprovação do comitê de ética: Não aplicável.

Disponibilidade dos dados da pesquisa: Todos os dados gerados ou analisados neste estudo estão incluídos no manuscrito.

Contribuição dos autores: Idealização, investigação e execução da pesquisa: GOMES, A. F.; PASSINHAS, D. M. C.; SANTOS, E. A.; CARNEIRO, E. S.; JESUS, J. S. de; FIGUEIREDO, N. F. Condução, revisão metodológica, correção e revisão total do manuscrito: GOMES, A. F.; PASSINHAS, D. M. C.; SANTOS, E. A.; CARNEIRO, E. S.; JESUS, J. S. de; FIGUEIREDO, N. F. 